\title{
Damage due to start-stop cycles of turbine runners under high-cycle fatigue
}

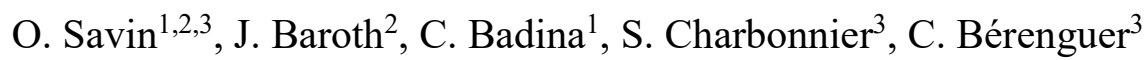 \\ ${ }^{1}$ General Technical Division, Electricité de France, F-3800 Saint Martin le Vinoux, France \\ 2 Univ. Grenoble Alpes, CNRS, Grenoble INP**, 3SR, F-38000 Grenoble, France \\ 3 Univ. Grenoble Alpes, CNRS, Grenoble INP**, Gipsa-Lab, F-38000 Grenoble, France
}

Corresponding author: julien.baroth@univ-grenoble-alpes.fr

\begin{abstract}
:
This study presents a strategy to estimate the extra cost due to start-up and shut-down of hydro turbines under high-cycle fatigue. The principle is to compare estimations of cumulated damages from three elementary sequences representing steady and transient regimes (start and stop cycles) of turbine runners, from in-situ strain measurements. Rainflow cycle-counting is used to extract stress cycles from these three sequences. Fatigue design curves are defined, taking into account design codes, laboratory tests and a probabilistic approach. The analysis of these curves, coupled with the Palmgren-Miner rule, allows estimating damage ratio, i.e. extra costs of start and stop events, through an equivalent number of normal operating hours. This approach is applied to Francis and Pelton runners. Different results are discussed in terms of damage distributions and extra costs of start and stops.
\end{abstract}

Keywords: start and stop, turbine, high cycle fatigue, Wöhler curve, turbine, rainflow cyclecounting, Palgrem-Miner, damage, Francis runner, Pelton runner 
Nomenclature.

\begin{tabular}{llll}
\hline Sigle & Description & Sigle & Description \\
\hline EdF & Électricité de France & SS & Start and stop \\
SRH & EdF Hydraulic reparation service & $S-N$ curve & Stress vs Number of load cycles \\
GE & General Electric & FFT & Fast Fourier Transform \\
ASME & American Society of Mechanical Engineers & $\mathrm{N}_{\text {noh }}$ & Number of normal operating \\
RCC-M & Design and Construction Rules for Mechanical & & Hours \\
& Components & FEM & Finite Element Model \\
\hline
\end{tabular}

Table 2

30 Main notations.

\begin{tabular}{|c|c|c|c|c|c|}
\hline Symbol & Parameter & Unit & Symbol & Parameter & Unit \\
\hline$Y S, U T S$ & $\begin{array}{l}\text { Yield and ultimate tensile strengths of } \\
\text { steel }\end{array}$ & $\mathrm{Pa}$ & $E$ & Young's modulus & $\mathrm{Pa}$ \\
\hline$\sigma$ & Stress & $\mathrm{Pa}$ & $\varepsilon$ & Strain & $\mu \mathrm{m} / \mathrm{n}$ \\
\hline$\sigma_{a}$ & Applied stress amplitude & $\mathrm{Pa}$ & $\sigma_{m}$ & Mean stress & $\mathrm{Pa}$ \\
\hline$\sigma_{n o m}$ & Nominal stress amplitude & $\mathrm{Pa}$ & $\sigma_{\min }, \sigma_{\max }$ & Minimal, maximal stress & $\mathrm{Pa}$ \\
\hline$F E L$ & Fatigue endurance limit & $\mathrm{Pa}$ & $D$ & Damage & - \\
\hline$N r$ & $\begin{array}{l}\text { Number of load cycles to failure } \\
\text { (Fatigue life) }\end{array}$ & - & $d_{s t}, d_{s p}, d_{s y}$ & Elementary damages & - \\
\hline$N$ & Number of load cycles & - & $\Delta t_{s t}, \Delta t_{s p,} \Delta t_{s y}$ & Durations & - \\
\hline$\sigma_{D}(N)$ & Endurance limit for $\mathrm{N}$ cycles & $\mathrm{Pa}$ & $t$ & Time & $\mathrm{S}$ \\
\hline$K_{t}$ & (Fatigue) stress concentration factor & - & $\mu, s$ & Mean, standard deviation & - \\
\hline$R$ & Stress ratio $\sigma_{\min } / \sigma_{\max }$ & - & $C V$ & $\begin{array}{l}\text { Coefficient of variation } \\
\mathrm{CV}=\mathrm{s} / \mu\end{array}$ & - \\
\hline
\end{tabular}

\section{Introduction}

During the last decades, hydro-power plants have been working with an increasing number of start and stop cycles to balance the electric network. Power fluctuations are generated to integrate new types of energy in the electrical grid, but start and stop cycles events are particularly damaging (Gagnon et al. 2010). As a consequence, estimating the cost incurred by start and stop cycles because of increased damage becomes crucial to develop short and longterm operating strategies.

Start and stop cycles events induce degradation of various mechanical equipments of the plants, such as the turbine, penstock and main shut-off valve. Hydroelectric turbines runners are one of the most expensive components to be potentially repaired (Savin et al. 2020). It is also known that fatigue and cavitation are the two main degradation mechanisms of these runners (Dojčinović et al. 2017, Gagnon et al. 2018), among other failure modes (Liu et al. 2016). Fatigue is often considered as the most difficult to manage, particularly in case of fatigue 
cracking (Arsić et al. 2013, Dorji \& Ghomashchi, 2014, Liu et al., 2016, Luna-Ramirez et al., 2016).

Our aim in this work is to propose a method to quantify the additional cost due to the increased damage on the runners by fatigue due to the starts and stops. This aim in view, two approaches are used for the fatigue assessment (Balaji Rao et al. 2019). On the one hand, some models are based on crack growth and failure criteria (Susmel, 2008, 2009); crack development can occur on the buckets or blades of the turbine runners (Kokko et al. 2014, Welte 2008), Doujak 2016), Hassanipour (2015), Gagnon et al. 2010). On the other hand, some models are based on the relation between the magnitude of the alternating stress history $v s$ the number of cycles to failure (S-N curves) in combination with Palmgren-Miner's damage accumulation rule (Marcouiller \& Thibaut, 2015). Aiming to quantify the extra cost of start and stops of inservice turbines, this last kind of models is retained.

The proposed approach is based on the analysis of strain measurements near the critical areas where maximum stresses are concentrated in the stainless-steel runner. The analysis of these measurements is based on the selection of steady-state and transient sequences and on the use of rainflow cycle-counting (Matsuishi \& Endo, 1969, Amzallag et al. 1994). From the resulting cycle histograms, damage is estimated using a $S-N$ curve (Wöhler curve). Such a model linking the stress history and the number of cycles to failure is an engineering tool used for a long time (Wöhler, 1860), but still various works are developed to properly design it for fatigue life prediction (Susmel et al. 2014, Saga et al. 2020). Particularly, it is crucial to account for the stochastic nature of fatigue damage process (Schijve, 2005). This aim in view, probabilistic $S-N$ curves, denoted $P-S-N$, allow accounting for large dispersion of fatigue test data (Gagnon et al. 2013).

In this work, we will discuss both the use of design curves, modified using both $P-S-N$ and a regulatory curve, as defined using RCC-M (AFCEN, 2008) or ASME (Chopra \& Shack, 2003, ASME, 2013). Then, Palmgren-Miner's law is used to estimate cumulative damage (Marcouiller \& Thibaut, 2015), for each transient sequence (start-up and shut-down). Finally, we determine the equivalent number of normal operating hours $N_{\text {noh }}$ for each start or stop cycle. Such a number can be estimated from expert judgment. Nilsson \& Sjelvgren (1997) suggested that one start and stop is equivalent to 15 hours of normal operation. In the same paper, the value of 50 hours for a start and stop is also reported from Mjølsnes, 1999, found in Bakken, 2002 (see also Bakken \& Bjørkvoll 2002, Bureau of Reclamation 2014). Anyhow, these values are not properly justified, and to the best of our knowledge, no scientific publication can be found to present in detail how to estimate $N_{\text {noh }}$ from in-situ strain measurements, except in brief 
conference communications in French (Jacquemoud, 1994) and in French confidential reports (Ballester 1992, EdF \& GE, 2018). It is why we propose in the following to present and develop the approach, specifying all the underlying assumptions.

An instrumented Francis runner has been chosen as an example. Such equipment has been designed to start on Monday and to stop on Friday, but nowadays, the start and stop cycles frequency has been drastically increased. It is then crucial to better quantify the effect of these transient sequences.

The first section of the paper highlights consequences of start and stops on the lifetime of turbine runners. It also briefly reminds usual practice to account for fatigue phenomenon. Then a practical fatigue assessment method is presented, estimating damage ratios due to runners start and stops. Then, the method is applied to Francis runners. Finally, conclusions are drawn, highlighting limits and perspectives of the approach.

\section{Problem statement}

This section is first focused on turbine runners, undergoing fatigue due to start and stop cycles. Then $S-N$ curves classically used for fatigue assessment are introduced. Finally, a discussion about the extra cost due to start-up and shut down operations is proposed.

\subsection{Turbine runners under fatigue}

Common Francis turbines are composed of a runner band, runner crown and fixed blades (Fig. 1). These constructions are casted using stainless steels in 13-17\% $\mathrm{Cr}$ martensitic (Buxbaum \& Ostermann, 1983), (Sonsino \& Dieterich, 1990). Particularly, we will consider 13CR-4Ni (or DIN GX5CrNi 13-4), denoted "13-4 stainless steel” in the following. Runners undergo various several transient phenomena, as pointed out by Huth (2005): unsteady loading conditions can be induced by out of phase synchronization during start-up, modification of operating point, earth fault, (emergency) shut-downs (Nicolet et al. 2003). Particularly, start and stop cycles of Francis turbines runners are associated to transverse vibration, caused by high-frequency pressure fluctuations (irregular fluid flow, see Huth, 2005).

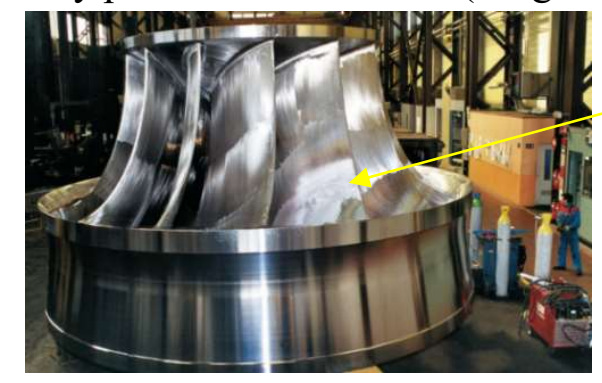

blade

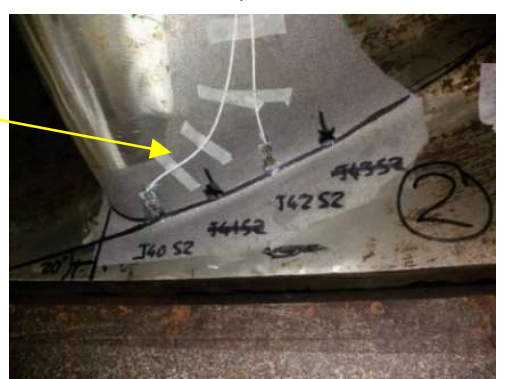

Fig. 1. Francis turbines: a) example of a runner ${ }^{\circledR} E d F$, b) welded joint of a blade (EdF \& GE, 2018). 
110 High-cycle fatigue (HCF) occurs, with associated deformation in every cycle remaining elastic,

111 i.e. the maximum stress in the runner, denoted $\sigma_{\max }$, remaining under the steel yield strength

112 YS (Jabbado, 2006). Highest stresses usually appear at blade welds with the band and crown

113 where each blade is fixed (Fig. 1). Figures 2 and 3 provide examples of strain histories in the

114 cases of two different turbines (Francis Fig. 2 and Pelton Fig. 3). Figure 2 shows the turbine

115 start (a) and stop (c) phases and the steady operating period (b) in the case of a Francis runner.

116 Figure 3 also show examples of unsteady steady sequences, in the case of a Pelton runner. In

117 such a figure, different strain evolutions can be observed for different power levels (Fig. 3a)

118 and also for start and stop sequences, coupled with steady state sequences (Fig. 3b) and only

119 used to help a pump to start ("back-to-back" start-ups, Fig. 3c).

120 These evolutions show very different unsteady behaviors. Figure 2 shows that the strain

121 amplitude in steady state is less significant compared to a few seconds of start-up or shutdown,

122 whereas Therefore Figure 2 seems to highlight that the cost of one hour in steady state is

123 insignificant compared to a few seconds start-up or shutdown.

124

125

126

127

128

129

130

131

132

133

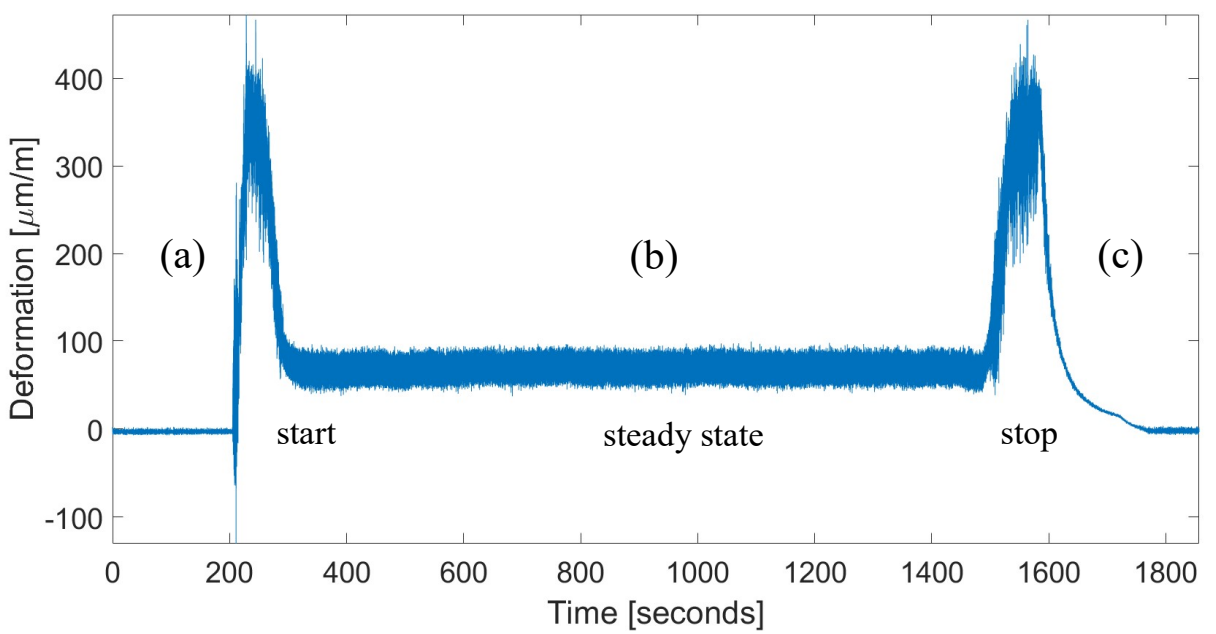

Fig. 2. Evolution of strain measurements for 3 loading sequences (Francis runner) ${ }^{\circledR E}$ EdF.

135

136

$$
1^{900}
$$

$\mu \mathrm{m} / \mathrm{m}$

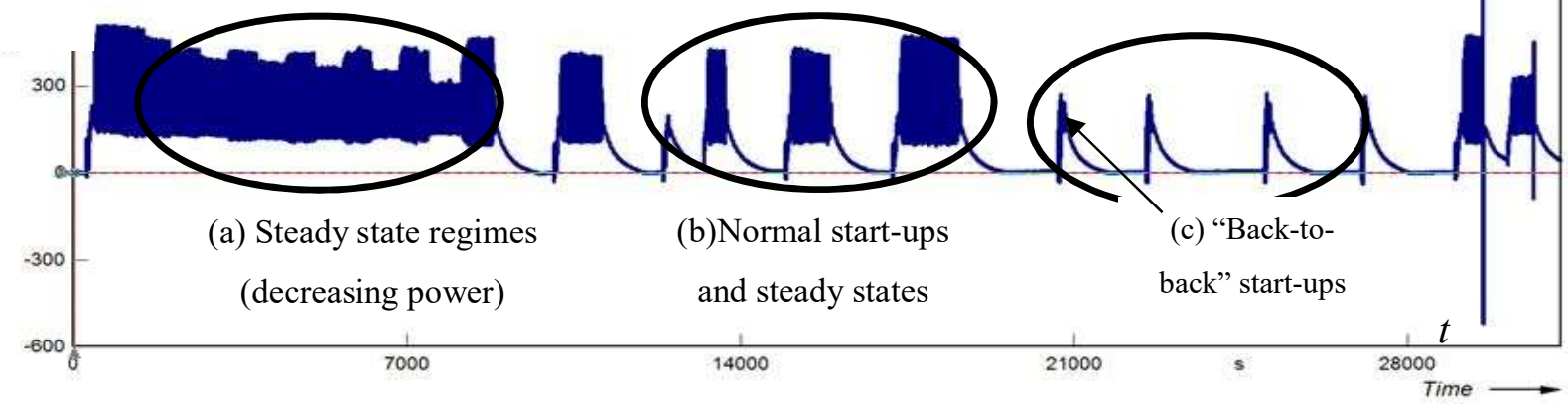

Fig. 3. Evolution of strain measurements for various loading sequences (Pelton runner) ${ }^{\circledR E d F}$. 
On the contrary, Figure 3 displays steady states (with different power ranges) with comparable strain amplitudes compared with start-ups and shutdowns (Fig 3a).

In the last two figures, the strain gauges were positioned near the critical points ("hotspots"), where the stress values (von Mises) are the highest. In the case of a Francis runner (figure 2), they were located at the junction between blade and crown and at the junction between blade and band; the first was analyzed because of higher recorded values. In the case of a Pelton runner (figure 3), gauges were located at the bucket root.

The stress history can be deduced from such strain measurements from the gauge the closest to the zone with the maximum stress $\sigma_{\max }$ in the runner. Denoting $\sigma_{\text {nom }}$ the nominal stress deduced from the gauge, one usually define the stress concentration factor $K_{t}$ as the ratio between $\sigma_{\max }$ and $\sigma_{\text {nom }}$.

$$
K_{t}=\frac{\sigma_{\max }}{\sigma_{\text {nom }}}
$$

In Fig. 4, an example of a stress signal during a simplified start-up sequence is shown, highlighting stress HCF cycles. Meanwhile, the whole start-up operation can be considered as a low-cycle fatigue (LCF) cycle, as it occurs less than $10^{6}$ times in the lifetime of the equipment. In this figure, stress amplitudes of HCF and LCF cycles are respectively denoted $\sigma_{a, H C F}$ and $\sigma_{a, L C F}$. The mean stress is denoted $\sigma_{m}$.

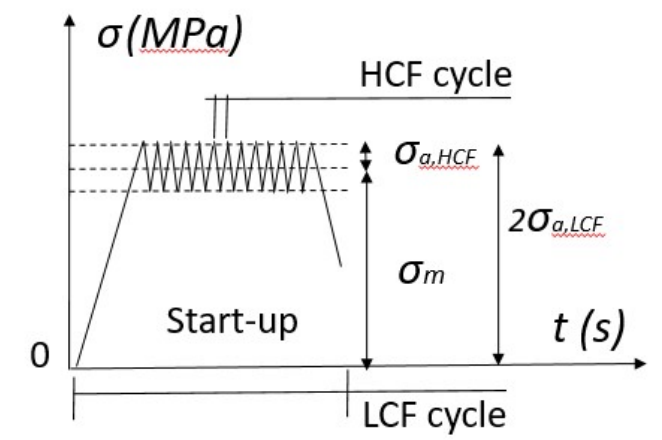

Fig. 4. Stress history highlighting a start-up sequence (runner scale).

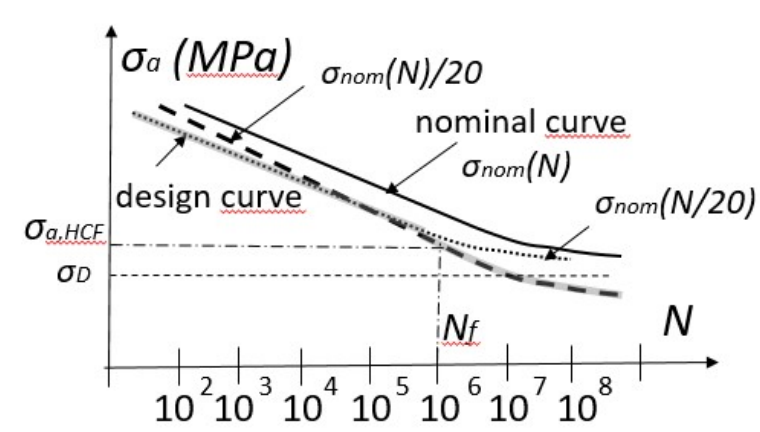

Fig. 5. $S-N$ curve: nominal and design curves (laboratory specimen scale).

\subsection{Fatigue assessment using regulatory or P-S-N Curves}

Fatigue assessment of a runner usually consists in using a $S-N$ curve, which is based on straincontrolled fatigue tests of small specimens at room temperature in air or in corrosive environment (see e.g. Buxbaum \& Ostermann, 1983) or (Sonsino \& Dieterich, 1990). Figure 5 displays a nominal $S-N$ curve and the corresponding fatigue endurance limit (FEL) under which the stress amplitude $\sigma_{a}$ will not lead to a failure, whatever the number $N$ of cycles (see Lei et 
al. 2021). Figure 5 also displays a design curve. For example, Figure 5 shows the regulatory number of cycles to failure $N_{f}$, related to the HCF stress amplitude $\sigma_{a, H C F}$.

172 The current nuclear design codes such as RCC-M (AFCEN, 2008) or ASME codes (Section III 173 fatigue design curves, see Chopra \& Shack 2003) define nominal curves as best-fit median 174 curves to the experimental test data accounting for modifications (in particular but not only): - to account for the effects of mean stress using the modified Goodman relationship

with UTS the ultimate strength of the runner material, $\sigma_{m}$ the mean stress, $\sigma_{\text {nom }}$ the nominal stress, and $\sigma_{a}$ the applied stress amplitude $(\mathrm{Pa})$.

- and then lowered by a factor $\gamma_{S}$ of 2 on stress and $\gamma_{N}$ of 20 on cycles to obtain the fatigue design curves.

184 These passage factors $\left(\gamma_{S}, \gamma_{N}\right)$ are supposed to cover conservatively two different effects: the variability of the lifetime under fatigue between laboratory tests and a structure within its real environment on the one hand, and between laboratory specimens on the other hand 187 (Grandemange \& Faidy, 2000), (Sudret, 2011). Chopra \& Shack (2003) underlined that these

188 factors are not safety margins but rather adjustment factors. They are not intended to address 189 all the environmental effects on fatigue life. For example, fatigue data obtained in the U.S. and Japan demonstrate that light water reactor environments can have potentially significant effects on the fatigue resistance of steels, such that the current ASME Code design curve can become nonconservative for certain materials. Moreover, RCC-M or ASME codes seem rather to be validated for fatigue lives under $N=10^{5}$ and $N=10^{6}$ respectively. These last two limits of

194 regulatory curves encourage to use probabilistic $S$ - $N$ curves (Balaji Rao et al. 2013, Fouchereau, 195 2014, Seddik, 2017). Indeed, $P-S-N$ curves can correspond to a given probability to get a lower 196 stress amplitude. Figure 6 depicts as an example a $P-S-N$ curve based on the common assumption of a Gaussian probability law modelling the nominal stress. 


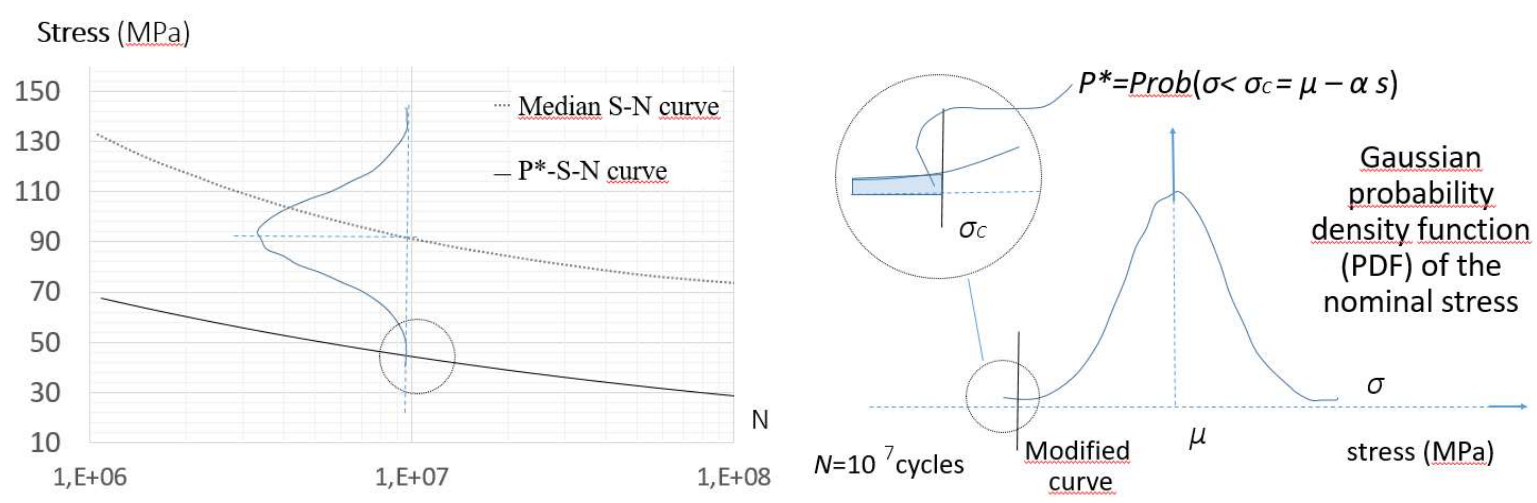

Fig. 6. Example of a design curve defined as a probabilistic $S-N$ curve.

The position of the design curve therefore depends on the knowledge of a standard deviation $s$ and a target probability $P^{*}$, defined in Eq. 5 (cf. Fig. 6 and Table 3).

Table 3

Target probability values $P^{*}$ depending on $\alpha$, such that $P^{*}=\operatorname{Prob}\left(\sigma<\sigma_{C}=\mu-\alpha s\right)$.

\begin{tabular}{llllll} 
Probabililty $\boldsymbol{P}^{*}$ & 0.05 & $10^{-2}$ & $10^{-3}$ & $10^{-4}$ & $10^{-5}$ \\
\hline
\end{tabular}

206 Passage factors $\left(\gamma_{S}, \gamma_{N}\right)$ become finally particularly relevant if a corresponding $P-S-N$ curve can 207 be defined. For instance, the use of a characteristic value can be considered, as it is defined in 208 design codes such as Eurocode (CEN, 2002). Particularly, a 5\% characteristic value $\sigma_{k}$, associated to a partial safety coefficient $\gamma$, could be defined such as

\subsection{The extra cost due to the increase of start and stop cycles}

213 In the simplified case presented Fig. 4, there is only one HCF stress amplitude $\sigma_{a, H C F}$, for $n_{H C F}$ 214 cycles, and one LCF cycle with stress amplitude $\sigma_{a, L C F}$. Then the damage caused by these 215 cycles can be written:

$$
d=\frac{1}{N_{f}^{L C F}}+\frac{n_{H C F}}{N_{f}^{H C F}}
$$

More realistically, an on-site stress history leads to a complex series of stress amplitudes

219 (see Fig. 2 and 3). For such complex loading history, histograms of stress amplitudes can be 220 extracted using a cycle-counting method such as rainflow method, Markov chain or ARMA 221 model methods (Ling et al. 2011). Figure 7 displays simplified distributions of cycles obtained 222 for the two damaging sequences of a Pelton turbine (Ballester 1992): full-power steady state 
(Fig 7a, corresponding to Fig. 3b setting), and "back-to-back" start-up sequence (Fig. 7b, 224 corresponding to Fig. 3c setting).

225

226

227

228

229

230

231

234

235

236

237

238

239

240

241

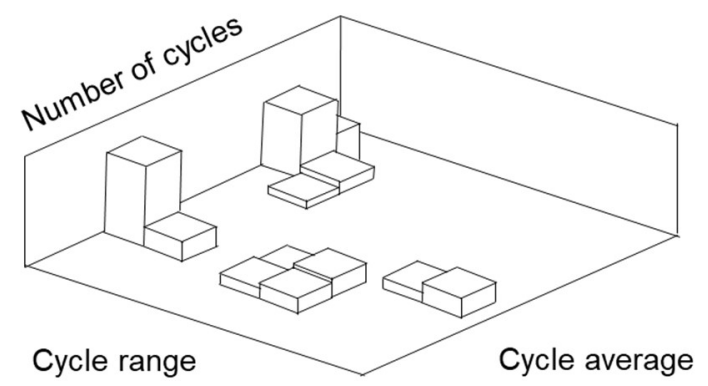

a)

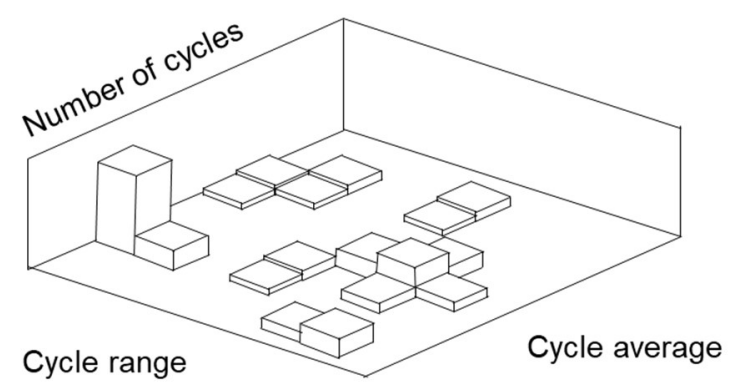

b)

Fig. 7. Simplified distributions of cycles extracted after a cycle-counting procedure: case (a) full-power steady state, and case (b) start-up sequence.

Damage corresponding to these cycles distributions is estimated using Palmgren-Miner's damage accumulation rule, summing elementary damages, more generally denoted $n_{j}$, such that

$$
d=\sum_{j=1}^{r} \frac{n_{j}}{N_{f, j}}
$$

The well-known cumulative damage method (EN 1993-1-9, 2005) means that a total damage is reached for $d=1$. However, such a rule does not help to estimate the lifetime of runners, given that this lifetime can be impacted by phenomena that cannot be measured using damage estimation.

In this paper, damage estimation principle only aims at comparing steady and unsteady sequences. The idea is to use cycle-counting to different sequences, then to extract damages and finally to compare them. Damage ratios could then help quantifying how start of stop sequences are more damaging (or not) compared to a supposed steady state.

The next section will present such an approach.

\section{Estimation of damage ratios due to runners start and stop}

This section presents how to estimate equivalent number of operating hours for start and stop events. Principle of this estimation is resumed in Fig. 8 and is explained. Then, a probabilistic $S-N$ curve is determined, based on fatigue tests data.

\subsection{Presentation of the approach}

The proposed method consists first in the instrumentation of the runners with strain gages (Fig. 8a) (Lofflad et al. 2014). The question whether extensometers (unidimensional gages 
instead of rosette gages) are sufficient has to be discussed. To do this, a finite element (FE) 251 model can be used to estimate the stress concentration factor $K_{t}$ (Bryla et al. 2013) and to confirm that uniaxial strain are representative of the real strain state (Morissette et al. 2016).

253 These strains are derived after gages signal processing, accounting for a gauge factor and after 254 filtering, accounting for signal noise (Fig. 8b). Finally, stresses are deduced by means of 255 Hooke's law and Young's modulus of the runner $E^{\text {runner }}$ and by checking that the maximum 256 stress is below the yield strength YS (Fig. 8c). Loading sequences are selected for start and stop 257 and steady states, with durations $\Delta t_{s t}, \Delta t_{s p}, \Delta t_{s y}$ (Fig. 8d). Then cycle counting allows obtaining 258 stress amplitudes $\sigma_{a}$ vs number of loading cycles $n_{j}$, for each sequence (Fig. 8e). A design curve is defined using $P-S-N$ curves based on laboratory tests on specimens (Fig. 8f). As a consequence, Palmgren-Miner's damage accumulation rule leads to elementary damages $d_{s t}$, $d_{s p}, d_{s y}$ (Fig. 8g) and damage ratios $d_{s t} / d_{s y}$ and $d_{s p} / d_{s y}$ (Fig. 8h) are deduced. Figure 8 summarizes 262 the main steps of the approach.

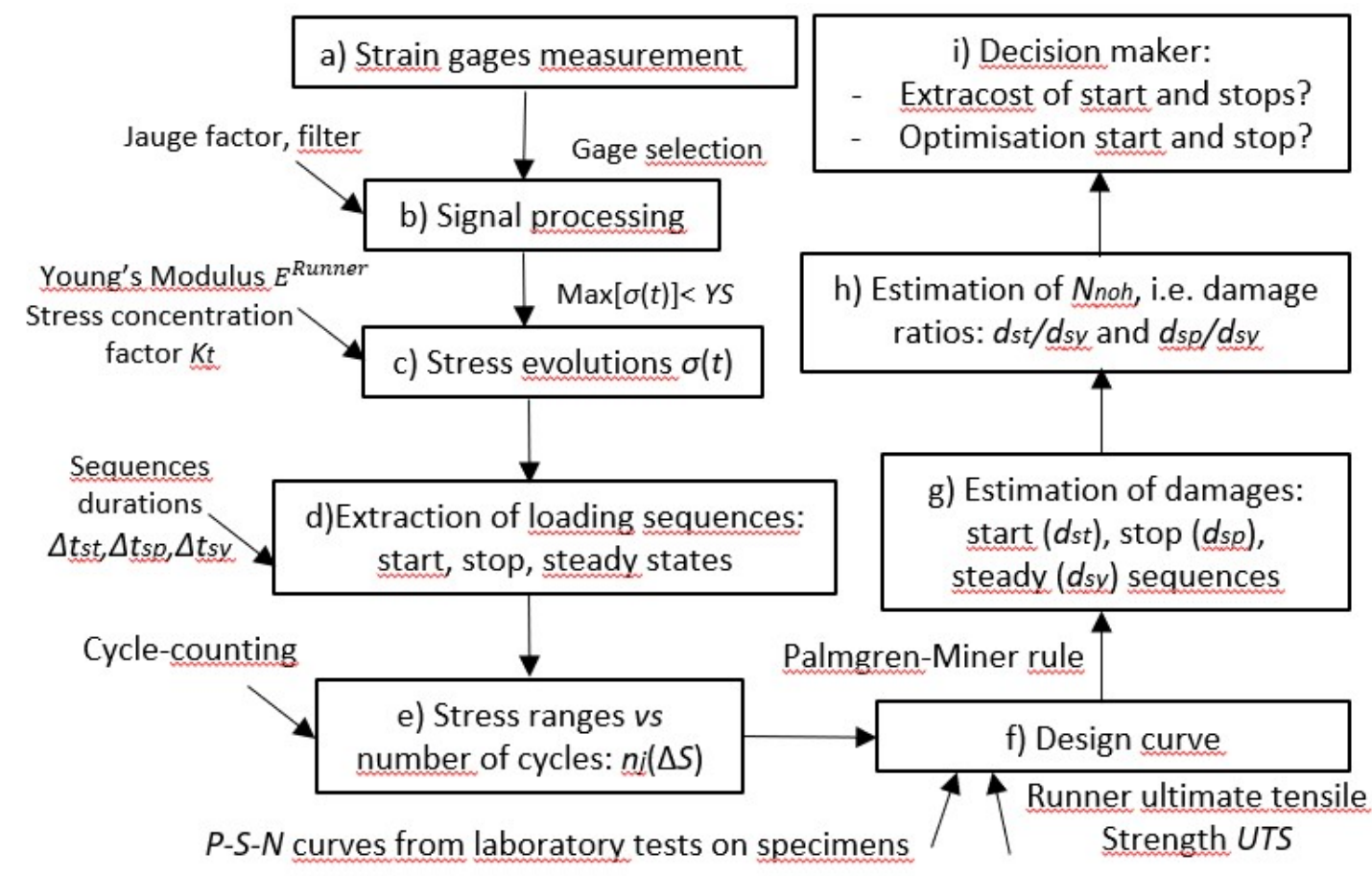

265 From these damage ratios are derived: equivalent numbers $N_{\text {noh }}$ of normal operating hours

267 where $\left(N_{\text {noh }}^{i}, \Delta t_{i}, d_{i}\right)$ denotes $\left(N_{\text {noh }}^{\mathrm{st}}, \Delta t_{s t}, d_{s t}\right)$ and $\left(N_{\text {noh }}^{\mathrm{sp}}, \Delta t_{s p}, d_{s p}\right)$ for start and stop transient 268 sequences respectively.

269 Elementary damages $d_{s t}, d_{s p}, d_{s y}$, denoted as $d_{j}$ in the following, are the ratios between the numbers of loading cycles $n_{j}$ and $N_{f, j}$. The number of cycles $n_{j}$ is given by a cycle-counting 
method (Fig. 8e). For example, Figure 9 displays distributions of elementary damage $d$, deduced

272 from histograms (Fig. 7) and using numbers of cycles to failure $N_{f, j}$ estimated from a $P^{*}=1 / 100$

$273 S$ - $N$ curve (Ballester 1992).

274

275

276

277

278

279

280

281

282

283

284

285

286

287

288

289

290

291

292

293

294

295

296

297

298

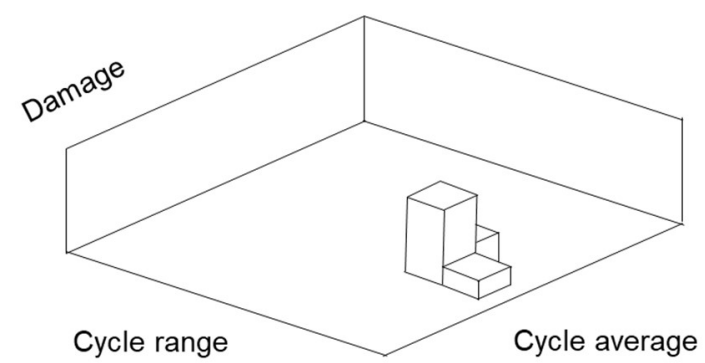

a)

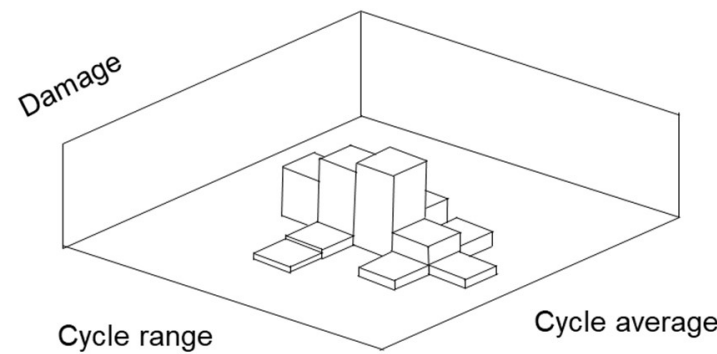

b)

Fig. 9. Simplified distributions of damage: case (a) full-power steady state, compared to start-up sequence case (b), with more cycles and cycle ranges, leading to more damage.

In the case of full-power steady state (Fig. 7bis a), most damaging cycles are those corresponding to the stresses after water impact: on the blades in the case of Francis runners, on the buckets in the case of Pelton runners. As an example, in the case of back-to-back start of a pump (Fig. 7bis b), Ballester (1992) estimated that the accumulation of damage of the Pelton runner leads to $N_{\text {noh }}=3$ times the total damage found in case a).

The next section presents how to define the cycles number at failure $N f_{j}$. using a design curve, based both using probabilistic and regulatory $S$ - $N$ curves, as proposed.

\subsection{Probabilistic $S-N$ curves}

This section is divided into three parts: i) the presentation of fatigue test series, ii) the modified Goodman relationship, taking into account the effect of mean stress, iii) the estimation of $P-S-N$ curves in accordance with the design rules.

\section{Fatigue test series}

Series of tests were carried out on dozens of specimens, under axial and also combined axial and lateral cyclic loading, on 2 types of specimens and several steel grades (Buxbaum \& Ostermann, 1983). These tests have been carried out in the same conditions as industrial runners. They are extracted from large-sized casted blocks. The size of the specimens is consistent with the dimensions of the runners. Only 13.4 steel with yield strength $Y S=628 \mathrm{MPa}$ and ultimate strength $U T S=804 \mathrm{MPa}$ is used here. Figure 10 shows the two types of specimens, which correspond to:

- axial cyclic tests: the stress is assumed to be homogeneous in cross-section, which leads to a stress concentration factor $K_{t}$ of 1 ; 
- combined axial and lateral cyclic tests composed of notched prismatic specimens, with $K_{t}$

300 equal theoretically to 1.36 .

301

302

303

304

305

306

307

308

309

310
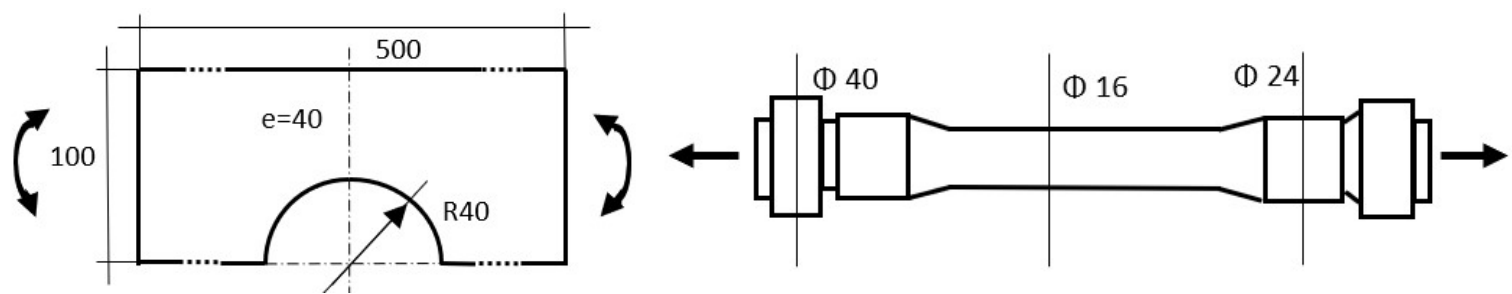

Fig. 10. Specimen under flexural bending (left) and tension (right) (Buxbaum \& Ostermann, 1983), cf. Table 4

Table 4 gathers configurations depending on test conditions in air or in corrosive environment and on the zero mean stress levels $(R=-1)$, equal to $204 \mathrm{MPa}$, or $\sigma_{\text {nom }} / 2(R=0)$. For each combined axial and lateral cyclic test, stresses are deduced from measurements at the edge or center of the specimens (series $4 \mathrm{~b}$ and $4 \mathrm{c}$ ). A theoretical stress concentration factor $K_{t}$ is given. In the following, we particularly study tests series 3 and 4 , because they have been carried out in corrosive environment similar to the one of industrial runners.

\section{Table 4}

Synthesis of test series (Buxbaum \& Ostermann, 1983), cf. Fig. 10.

\begin{tabular}{lllll}
\hline $\begin{array}{l}\text { Series } \\
\text { d'essais }\end{array}$ & Environment & $\begin{array}{l}\text { Type of mechanical } \\
\text { loading }\end{array}$ & $\begin{array}{l}\text { (Ratios of) stress } \\
\text { min., moy. max. }\end{array}$ & $\begin{array}{l}\text { Theorical stress } \\
\text { concentration factor }\end{array}$ \\
\hline 0 & air & Alternate tension & $R=-1, \sigma_{m}=\sigma_{\text {nom }} / 2$ & 1 \\
1 & air & Alternate tension & $R=0, \sigma_{m i n}=0 \mathrm{MPa}$ & 1 \\
$3 \mathrm{~b}(3 \mathrm{c})$ & corrosive & Alternate bending & $R=0, \sigma_{m i n}=0 \mathrm{MPa}$ & $1.36(1)$ \\
$4 \mathrm{~b}(4 \mathrm{c})$ & corrosive & Alternate bending & $\sigma_{m}=204 \mathrm{MPa}$ & $1.36(1)$ \\
\hline
\end{tabular}

Table 5 presents some statistics on selected test series. The dispersion of the measurements is estimated by the coefficient of variation of the stress amplitude $\sigma_{a}$ for $N=10^{7}$ cycles. Figure 11

316 also shows the dispersion of the measurements. This coefficient of variation fluctuates from

317 about 10 to $20 \%$ depending on the series, with an increasing trend for higher mean stress.

\section{Table 5}

319 Stress amplitudes $\sigma_{a}$ in cases of series $0,1,3,4$ (Buxbaum \& Ostermann, 1983).

\begin{tabular}{cccccc}
\hline $\begin{array}{c}\text { Tests } \\
\text { series }\end{array}$ & $\begin{array}{c}\text { Tests } \\
\text { number }\end{array}$ & $\begin{array}{c}N \text { variation } \\
\text { domain } \Delta\end{array}$ & $\begin{array}{c}\text { Stress } \sigma_{a} \\
N=10^{7}(\mathrm{MPa})\end{array}$ & $\begin{array}{c}\text { Mean stress (MPa) } \\
\text { (Standard deviation) }\end{array}$ & $\begin{array}{c}\text { Coefficient } \\
\text { of variation }\end{array}$ \\
\hline 0 & 15 & $4.10^{5-2,3.10^{7}}$ & 182 & $32(24)$ & 0.21 \\
1 & 18 & $2.10^{6-}-10^{8}$ & 110 & $13(9)$ & 0.14 \\
$3 \mathrm{~b}$ & 15 & $1.610^{6-1}-10^{8}$ & 92 & $9(8)$ & 0.14 \\
$3 \mathrm{c}$ & 8 & $2.510^{6-1}-10^{8}$ & 74 & $5(5)$ & 0.11 \\
$4 \mathrm{~b}$ & 9 & $6.10^{5-10^{8}}$ & 65 & $6(4)$ & 0.09 \\
$4 \mathrm{c}$ & 14 & $2.10^{6-10^{8}}$ & 52 & $6(5)$ & 0.16 \\
\hline
\end{tabular}




\section{Accounting for the mean stress and stress concentration factor}

Table 6 presents these modifications for $N=10^{7}$ and $10^{8}$ load cycles, in the case of series 3 and 4, with measurements at the edge and in the center of the specimens. Two types of modification can then be estimated:

329 - taking into account the mean stress: modified Goodman relationship, from 4 to $25 \%$;

330 - the stress concentration factor $K_{t}$, estimated here between 1.23 and 1.4 (1.36 theoretically).

Table 6

332 Modified stress amplitudes (MPa) depending on the mean stress, for test series 3, 4 de (Buxbaum \& Ostermann, 333 1983), 13.4 steel, ultimate limit strength of $804 \mathrm{MPa}$, from measurements at the edge and center of specimens Specimen edge Specimen center (close to the notch) $K_{t}$ tests

Series $3 b$ (edge) and $3 c$ (center) : case $R=0$, i.e. $\sigma_{\min }=0 M P a$ and $\sigma_{m}=\sigma_{a} / 2$

\begin{tabular}{lllllllll} 
& $\sigma_{a}$ & Correct.(\%) & $\sigma_{\text {nom }}$ & & $\sigma_{a}$ & \multicolumn{2}{c}{ Correct.(\%) } & $\sigma_{\text {nom }}$ \\
\hline$N=10^{7}$ & 72 & 4.5 & 75 & $N=10^{7}$ & 59 & 3.7 & 61.2 & 1.23 \\
$N=10^{8}$ & 90 & 5.6 & 95 & $N=10^{8}$ & 74 & 4.6 & 77.6 & 1.23
\end{tabular}

Series $4 b$ (edge) and 4c (center): case $\sigma_{m}=204 \mathrm{MPa}$

\begin{tabular}{lllllllll} 
& $\sigma_{a}$ & Correct.(\%) & $\sigma_{\text {nom }}$ & & $\sigma_{a}$ & \multicolumn{2}{c}{ Correct.(\%) } & $\sigma_{\text {nom }}$ \\
\hline$N=10^{7}$ & 52 & 25.4 & 70 & $N=10^{7}$ & 37 & 25.4 & 49.6 & 1.41 \\
$N=10^{8}$ & 70 & 25.4 & 94 & $N=10^{8}$ & 54 & 25.4 & 72.4 & 1.30
\end{tabular}

334 The stress concentration factor of 1.36 is not exactly found, partly because of the uncertainties

335 in the stress estimate and partly because it seems unlikely that the maximum stress was

336 accurately measured at the center of the specimens. For safety reasons, $K_{t}=1.36$ will be 337 considered in the following. 


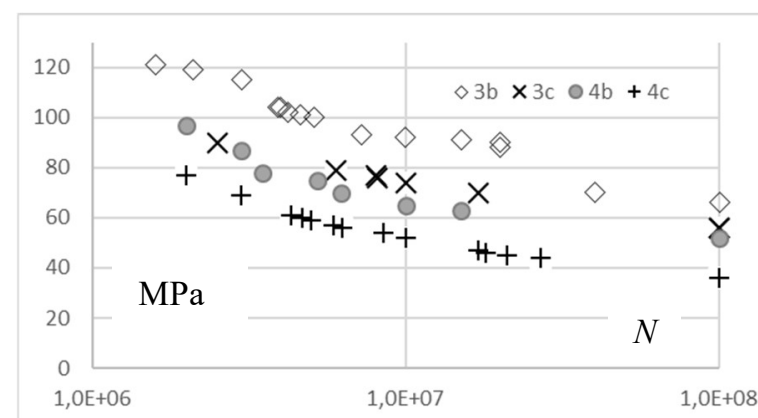

a) before Goodman modifications

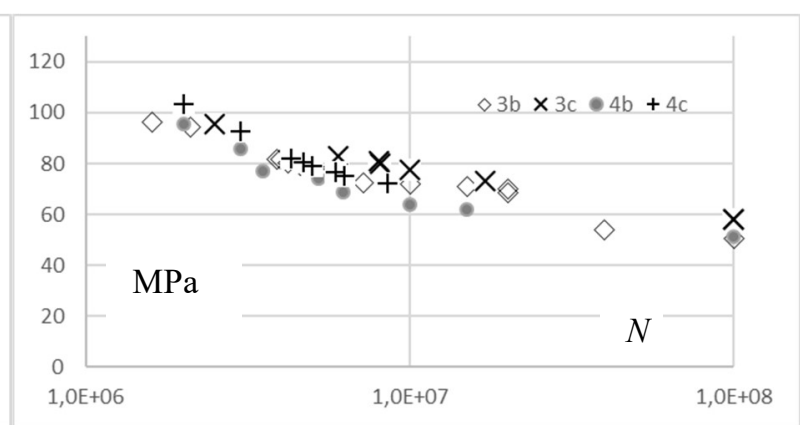

b) after Goodman modifications (see Eq. 2)

Fig. 12. Mean $S$ - $N$ curves (13.4 steel), series 3b, 3c, 4b, 4c

\section{Looking for nominal and design $\boldsymbol{S}-\boldsymbol{N}$ curves}

342 In order to carry out a fatigue design, it is necessary to define a nominal curve, which can in 343 principle be deduced from each of the 4 above-mentioned curves. Figures $12 \mathrm{a}$ and $12 \mathrm{~b}$ show 344 the mean Wöhler curves of series 3 and 4, derived from measurements at the edge and center of the specimens, before and after Goodman modifications. If we do not use the mean curves, but all the stress amplitudes, we obtain an average dispersion of $13 \%$, which is the average coefficient of variation that can be deduced from Table 3. Defining a nominal curve could then consist of a regression of one curve among others or of the mean points of Fig. 12b. Equation 9 provides the equation of the regression for all series 3 and 4 .

This $50 \% S-N$ curve is plotted on Fig. 13., with different corrected design curves. Indeed, one considers at least three options:

- a) a $P-S-N$ curve; Figure 13 a proposes $0.1 \%$ and $0.01 \% S-N$ curves, deduced from the $50 \% S$ - $N$ curve (Eq. 8), and following Table 1 and Eqs. 4-5;

- b) a regulatory curve deduced from the $50 \% S-N$ curve (Eq. 8), applying the design rule

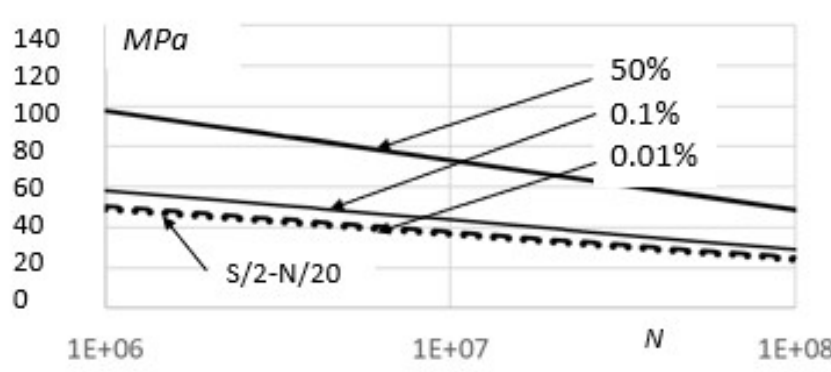

a) Mean regression curve $\sigma_{a}, P=10^{-2}$ and $10^{-4} S-N$ curves and corrected $S$ - $N$ curve according to (AFCEN, 2008), (Chopra \& Shack, 2003)

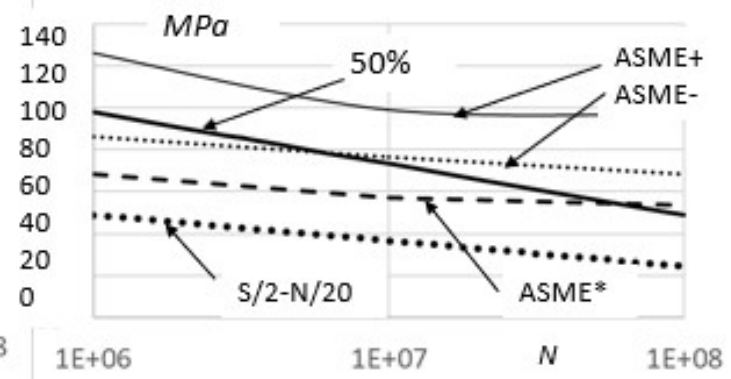

b) Nominal curves for highly and poorly alloyed steel (ASME, 2013), compared with other curves

Fig. 13. Corrected design S-N curves deduced from the mean experimental series (a), from ASME code (b). 
369 Last option, c) curves denoted ASME+ and ASME-, respectively, correspond to carbon and 370 low-alloy steels (Young's modulus $E$ of $206.8 \mathrm{GPa}$ ) and austenitic stainless steels $(E=$ $371195.1 \mathrm{GPa}$ ) (ASME, 2013). Contrary to $P-S-N$ curves deduced from the presented experimental 372 series, ASME $S$ - $N$ curves do not account for any corrosive environment, justifying arbitrarily 373 corrected $S$ - $N$ curve by dividing nominal stress values by a safety factor, e.g. 1.5 (see Brand et al., 1999). Therefore Figure $13 \mathrm{~b}$ shows the revised $S-N$ curve, denoted ASME*, accounting for this coefficient and also a $200 \mathrm{GPa}$ Young's modulus. It is worth noting that if this revised curve is conservative for $N<10^{7}$, it becomes far less conservative for larger number of cycles, which corroborates the analysis found in Chopra \& Shack (2003), in the case of a usual fatigue assessment.

\section{Application to Francis and Pelton runners}

381 Method presented in the section 2 is applied here to Francis and Pelton runners. Considered runners are listed in Table 7. They are all made using 13.4 steel, with Young's modulus of $200 \mathrm{GPa}$. Signal filtering and cycle counting are applied in four cases, before estimating damage ratios, i.e. equivalent number of normal operating hours. For all studies, signals were acquired at a $2400 \mathrm{~Hz}$ frequency with an anti-aliasing filter.

List of runners (EdF fleet of hydroelectric power plants).

\begin{tabular}{lll} 
& Runner type & Effective power \\
Runner 1 & Francis (turbine) & $28 \mathrm{MW}$ \\
Runner 2 & Francis (turbine) & $2 \mathrm{MW}$ \\
Runner 3 & Pelton (turbine) & $>80 \mathrm{MW}$ \\
Runner 4 & Pelton (Ballester, 1992) & $152 \mathrm{MW}$ \\
\hline
\end{tabular}

\subsection{Case of a 28 MW Francis runner (runner 1)}

This runner has been studied estimating a maximum stress of $60 \mathrm{MPa}$ (EdF \& GE, 2018), for an estimated maximum deformation of $300 \mu \mathrm{m} / \mathrm{m}$. However, the maximum deformation found (J1S8 gauge) is $132.5 \mu \mathrm{m} / \mathrm{m}$, which leads us to consider a stress concentration factor $K_{t}$ of 2.27 with an accuracy of about 3\% ( $K_{t}$ estimated between 2.16 and 2.34, EdF \& GE, 2018). For the power of $28 \mathrm{MW}, K_{t}=2.16$; is the coefficient we propose to consider in the following. 
A spectral analysis is performed to quantify the impact of all degradation phenomena occurring at the runner, and determine the filter to be applied to separate the real effects from the signal noise. Fast Fourier Transform was performed during 5 minutes-long stabilized operating signal (Fig. 14). The eigen frequency $F_{0}=n_{o} / 60=2.63 \mathrm{~Hz}$ directly depends on the rotational frequency of the runner, where $n_{0}=158 \mathrm{rpm}$ is the rated synchronous speed of the runner.

402

403

404

405

406

407

408

409

410

411

412

413

414

415

416

417

418

419

420

421

422

423

424

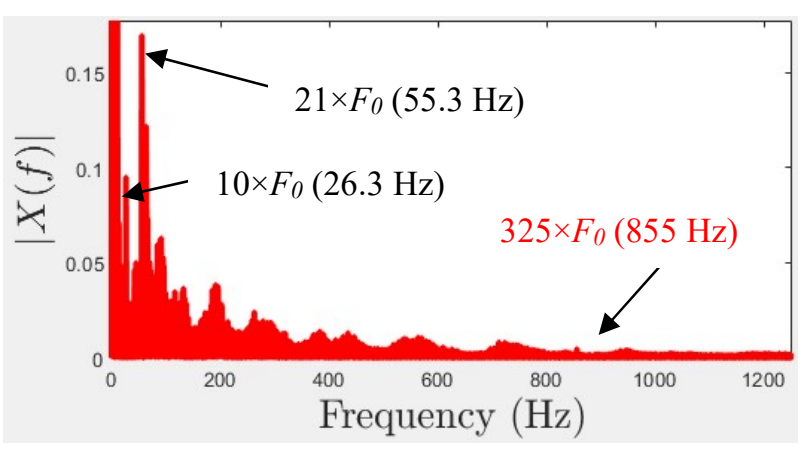

Fig. 14. Spectral analysis of the signal using a fast Fourier transform (FFT): evolution FT modulus vs frequency.
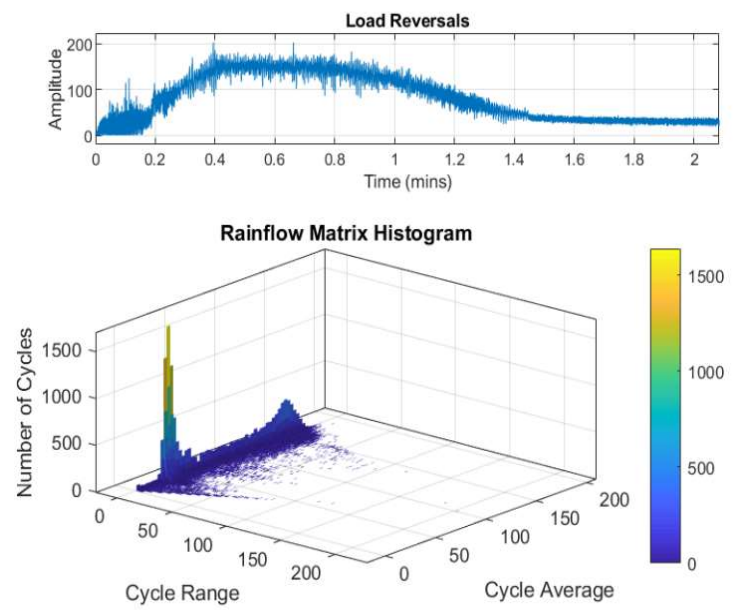

a)

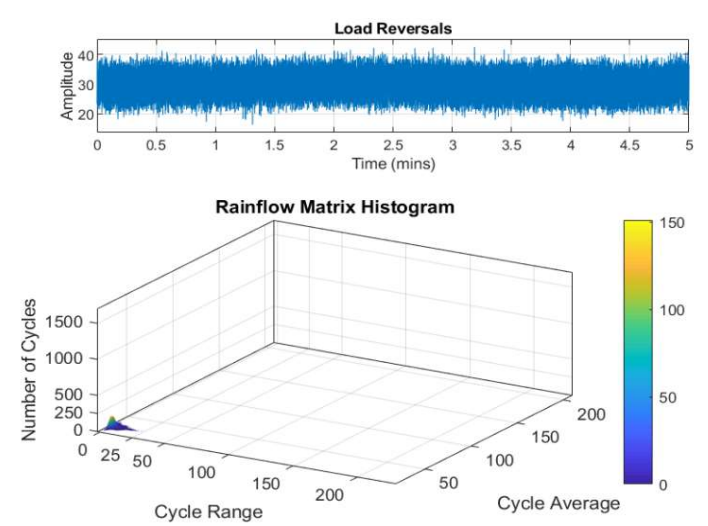

Fig. 15. Representation of the rainflow counting matrix using loading history of a steady regime.
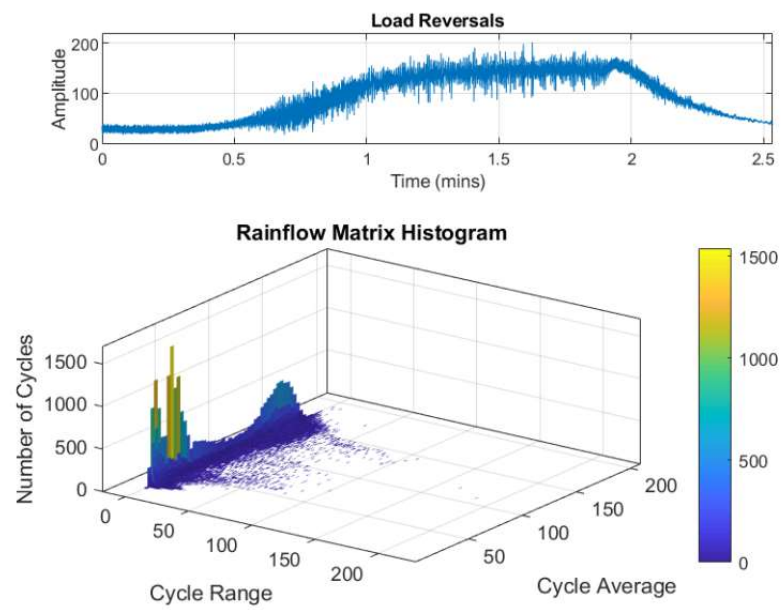

b)

Fig. 16. Representation of the rainflow counting matrix using a load history data in case of 28 MW startup (a) and stop sequences (b) (Runner 1).

The analysis shows harmonics at $2 \times F_{0}, 3 \times F_{0}$ up to $21 \times F_{0}$, with a natural frequency $F_{0}$ equal to 2.63 Hz. The harmonics captured in the spectrum could probably correspond to hydraulic instabilities e.g. to the $Z r=13$ blades $\left(Z r F_{0}=34.2 \mathrm{~Hz}\right)$, to the $Z s=24$ wicket gates $\left(Z s F_{0}=\right.$ $63.2 \mathrm{~Hz}$ )). The value of $855 \mathrm{~Hz}$ is an example that corresponds in fact to $25 \mathrm{Zr} \mathrm{F}$, harmonic of the interaction between the stationary pressure field (on the distributor side) and a rotating pressure field - (on the runner side)). At $55.3 \mathrm{~Hz}$ is detected the rotor-stator interaction and at $26.3 \mathrm{~Hz}$ interblades vortexes. 
The $1 \mathrm{kHz}$ filter is eventually applied in the following, given that ISO 20816-5 (2018) also recommends not filtering not below $1 \mathrm{kHz}$.

Rainflow counting algorithm (ASTM, 2011) is used to translate time-dependant stress loading into stress cycles amplitudes. For illustration, Figure 15 displays the steady state regime during $\Delta t_{s y}=5$ minutes, for a power stabilized at $28 \mathrm{MW}$, and a representation of the rainflow counting matrix, with histograms depending on amplitude (cycle range), mean stress (cycle average) and number of cycles.

Figures 16 represent the rainflow counting matrix using a load history data in the same case of a $28 \mathrm{MW}$ start-up (a) and shutdown sequences (b). Their durations are respectively equal to $\Delta t_{s t}=2 \mathrm{~min}$ and $\Delta t_{s p}=2.5 \mathrm{~min}$. On the histogram, fairly high numbers of cycles are reported compared to steady state sequence, where average cycles clearly less than $50 \mathrm{MPa}$.

\section{Estimations of damage and normal operating hours}

From this last observation, it seems irrelevant to account for an endurance limit. This can be checked displaying damage estimations for steady, start and stop sequences, with and without $30 \mathrm{MPa}$ fatigue endurance limit (FEL). This comparison is proposed in Fig. 17, accounting for arbitrarily FEL $=30 \mathrm{MPa}$, using ASME* (a) and $P=10^{-4}$ (b) $S$ - $N$ curves respectively. This figure highlights that the steady regime corresponds to stress amplitude mostly lower than the FEL. As a consequence, normal operating hours estimated in Tab. 6 increase drastically.

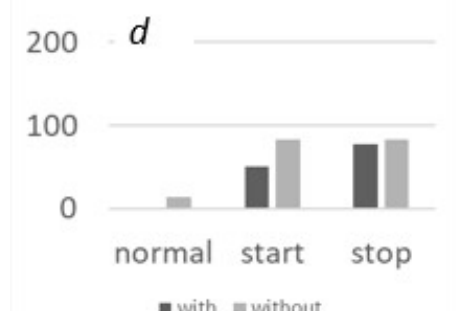

a) $\mathrm{ASME}^{*} S-N$ curve

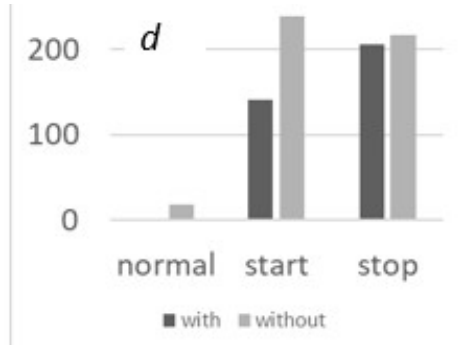

b) $P=0.1 \% S-N$ curve

Fig. 17. Representation of damage estimations for steady, start and stop sequences, with and without $30 \mathrm{MPa}$ endurance limit, accounting for ASME* (a) and $P=10^{-4}$ (b) $S-N$ curves respectively (runner 1).

Table 8 gathers estimations of normal operating hours ( $N_{\text {noh }}$, defined in Eq. 8$)$ obtained for runner 1, in cases of start and stop events. Three design curves presented in section 3 (Fig. 13) have been used to estimate damage ratios, considered as $N_{\text {noh }}$ estimations for these events (Fig. 16). For example, the first column provides the damage ratio (extracost) of a start-up, using the ASME* curve (Fig. 13b), without accounting for a fatigue endurance limit (FEL). It means that stress amplitudes below the FEL have been ignored to estimate elementary damages. 
456 Number of normal operating hours $\left(N_{n o h)}\right.$, start-up of the $28 \mathrm{MW}$ Francis (runner 1)

\begin{tabular}{llllll}
\hline Sequence & $A S M E^{*}$ & $A S M E^{*}$ & $P=0.1 \%$ & $P=0.1 \%$ & $P=0.01 \%$ \\
(with/without FEL) & without & with & without & with & without \\
Start-up & 6 & 51 & 13 & 141 & 658 \\
Stop & 6 & 78 & 12 & 205 & 423
\end{tabular}

457 Results from Table 8 seems conservative to account for the FEL. Anyhow, since most stress amplitudes of steady regime sequence being below the FEL, the operator better should consider them. Table 8 also shows that estimations of extra cost of start and stops highly depend on the choice of the $P-S-N$ curve: $N_{n o h}$ increases as $P$ decreases. For example, $N_{n o h}=141 \mathrm{~h}$ means that a start-up corresponds to $141 \mathrm{~h}$ of normal operating hours if we consider a $P-S-N$ design curve with $P=0.1 \%$ and if we account for the FEL in the estimation of the damage ratio $N_{\text {noh }}$. Moreover, runners' operator should bear in mind that $P-S-N$ curves are estimated from a limited number of tests, between $N=10^{6}$ and $10^{8}$ cycles, whereas damage estimation needs to use $S-N$ curves for higher $\mathrm{N}$ values. This last observation would then tend to recommend a regulatory curve such as ASME ones, defined to $N=10^{6}$ cycles. The operator has finally to choose a safety factor, arbitrarily equal to 1.5 in this work, but which should probably be taken larger.

\subsection{Other runners and discussion}

This section gathers results obtained using other runners (Tab. 5).

\section{Runner 2 (2 MW Francis turbine)}

This study was conducted using histories observed working on a runner similar to runner 1 . We consider the same material and also the same stress concentration factor. For technical reasons, we were only able to focus on a start-up of $2 \mathrm{MW}$. Figure 18 represents histograms of a start-up (a) and the steady state regime (b). In this case, a startup of less than 2 minutes corresponds to around 35 minutes of steady regime, using the $P=1 \% S-N$ curve. 

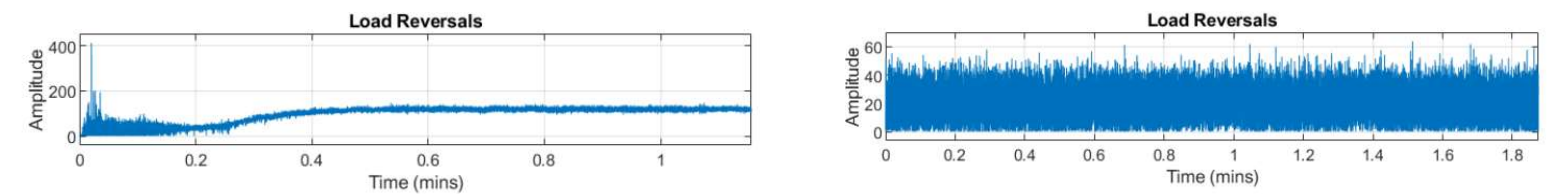

488
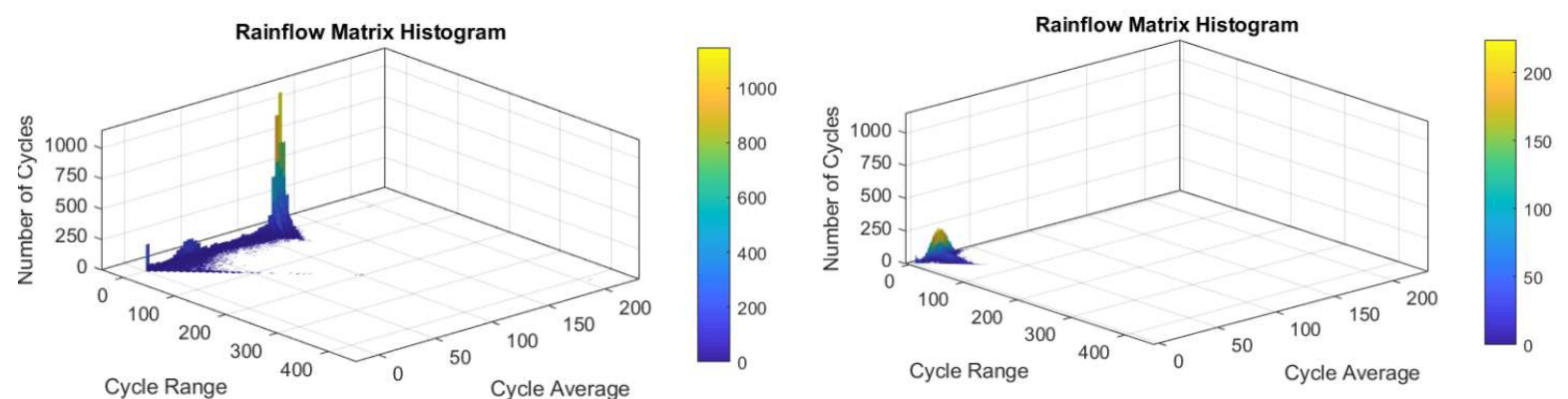

Fig. 18. Representation of the rainflow counting matrix for a Francis turbine in case of $2 \mathrm{MW}$ startup (a) and steady regime (b) (runner 2)

\section{Pelton runners 3 and 4}

Considered Pelton runners 3 and 4 are used to start a reversible machine in pump mode. Runner 3, with power greater than $80 \mathrm{MW}$, can be used to start a turbine-pump less powerful.

501 Runner 4 has the same power as the turbine-pump to be started (Ballester 1992). In this case,

502 the start-up of this runner is equivalent to 3 normal operating hours.

\section{Conclusion}

504 The paper presents a strategy to estimate the extra cost of start and stop of hydro turbines, under 505 high-cycle fatigue. The method compares estimations of cumulated damages from three 506 elementary sequences representing steady and transient regimes (start and stop cycles) of 507 turbine runners. These estimations are based on regulatory or probabilistic $S$ - $N$ curves, determined using fatigue tests data. The approach has been applied to Francis runners, using

509 also a past result on a Pelton runner, published only in French (Ballester 1992).

510 The proposed approach is interesting to detect and quantify extra cost of start and stop in terms

511 of normal operating hours. However the operator has to bear in mind that these estimations

512 depend on the reference $S-N$ curve used to estimate elementary damages. Laboratory tests or

513 regulatory curves are useful, but one has to use them with caution. For example, one of the 514 available ASME curves was designed for austenitic steel used in nuclear industry, but not used 515 for runners of hydraulic plants. 
Once an extra cost has been detected, the recommendation from Gagnon et al. (2010) can then be followed if possible, i.e. optimize this start-up scheme with regard to fatigue damage, in order to extend Francis runner life expectancy.

As perspectives, this approach could be applied to other ageing components such as penstock, or main shut-off valve. Ling et al. 2011 experienced to implement Markow chain or ARMA model method instead of rainflow cycle-counting method, that could also be improved (Anthes, 1997, Yung-Li et al. 2012).

\section{Acknowledgements}

The authors would also like to thank Philippe Bryla, Stéphan Courtin, Nicolas Dutruel, Thibaut

Autrusson, for their scientific advices.

\section{References}

AFCEN (2008): RCC-M - Edition 2007 - Addendum dec. 2008: Design and Construction Rules for Mechanical Components of PWR Nuclear Islands.

Amzallag, C., Gerey, J.P, Robert, J.L. and Bahuaud J., « Standardisation of the rainflow counting method for fatigue analysis », Int. J of Fatigue, Vol 16(4), 287-293, 1994.

Anthes R. J.. Modified rainflow counting keeping the load sequence. Int. J. of Fatigue, 19(7) :529—535, 1997.

Arsić, M., Karić, R., Sedmak, A., Burzić, M. and Vistać B., Methodological Approach to Integrity Assessment and Service Life of Rotating Equipment at Hydropower Plant - Turbine Shaft, Structural Integrity and Life, Vol.13, No.2, 2013, 117-124.

ASME, American Society of Mechanical Engineers Boiler and Pressure Vessel Code (ASME Code), Appendix I to Section III, "Rules for Construction of Nuclear Facility Components", 2013.

ASTM E1049-85(2017), "Standard Practices for Cycle Counting in Fatigue Analysis." West Conshohocken, PA: ASTM International, 2011.

Ballester, J.L. « Contribution to the study of the ageing of Pelton wheels: comparative damage ratios » (in French). Internal report EdF DTG MPSH, D.4100/EHM-G-92/08, 1992.

Bakken, B.H., (2002). Hydro unit startup costs and their impact on the short term scheduling strategies of swedish power producers. IEEE Power Engineering Society Summer Meeting.

Bakken B.H., Bjørkvoll T., « Hydropower Unit Start-up Costs », IEEE, 2002.

Balaji Rao, K., Anoop, M.B., Raghava, G., Prakash, M. and Rajadurai, A., Probabilistic fatigue life analysis of welded steel plate railway bridge girders using S-N curve approach. 2013, Proceedings of the Institution of Mechanical Engineers, Part O: Journal of Risk and Reliability 227: 385

Bureau of Reclamation, Hydrogenerator Start / Stop Cost, US 2014.

Brand, A., Flavenot J. F.; Gregoire R. and Tournier C., Technological data on fatigue, Senlis, CETIM, 1999, $4^{\mathrm{e}}$ ed., 383 p. (in French).

Bryla, P., Pillou, M. and Bennebach, M., Operation of the Bois plant hydraulic turbine in bypass operating mode: analysis of the fatigue behavior, Procedia Engrg 66 (2013), 413-450.

Buxbaum, O. \& Ostermann, H. Ausfallsichere Bemessung von Laufrädern für Wasserkraftmaschinen aus rostfreiem Stahlguss unter Berücksichtigung von Korrosion und Gefügezustand, Fraunhofer Institute for Structural Durability, Darmstadt, Germany, 1983. (Technical report in German)

CEN, 2002. Eurocode 0. Bases of Structural Design. Brussels: CEN.

Chopra, O.K. \& Shack, W.J., Argonne National Laboratory, Review of the Margins for ASME Code Fatigue Design Curve - Effects of Surface Roughness and Material Variability. U.S. Nuclear Regulatory Commission Office of Nuclear Regulatory Research Washington, DC 20555-0001, 2003. 
Dojčinović, M., Arsić, M., Bošnjak, S., Murariu, A. and Malešević Z., Cavitation resistance of turbine runner blades at the hydropower plant 'DJERDAP', Structural Integrity and Life, Vol.17(1), 2017, $55-60$.

Dorji, U. \& Ghomashchi, R. «Hydro turbine failure mechanisms: An overview », Engineering failure analysis 44 (2014) 136-147, Elsevier, 2014.

EN 1993-1-9 (2005): Eurocode 3: Design of steel structures - Part 1-9: Fatigue [Authority: The European Union Per Regulation 305/2011, Directive 98/34/EC, Directive 2004/18/EC].

EdF \& GE, « Prototype Air Injection Tests », confidential report, 2018

Fouchereau, R., Probabilistic modelling of S-N curves, PhD thesis, University Paris-Sud, 2014. (in French)

Gagnon, M., Tahan, S. A., Bocher, P. and Thibault, D. « Impact of start-up scheme on Francis runner life expectancy » 25th Iahr Symposium on Hydraulic Machinery and Systems, Iop Conf. Series : Earth and Environmental Science 12 (2010) 012107

Gagnon, M., Tahan, S. A., Bocher, P. and Thibault, D. « A probabilistic model for the onset of High Cycle Fatigue (HCF) crack propagation: Application to hydroelectric turbine runner » Int. J. Fatigue 47 (2013) 300-307.

Gagnon, M., Thibault, D. and Blain, M., « On the expected monetary value of hydroelectric turbine start-up protocol optimisation », $13^{\text {th }}$ world congress on Engrg Asset Managt, WCEAM, 2018.

Grandemange, J-M, Faidy C., General approach to preventing the risk of fatigue damage to nuclear boiler equipment: from design to monitoring during operation SFEN-ST2 Day "Fatigue damage to nuclear installations", Paris, 23 November 2000 (in French)

Hassanipour, M, Y. Verreman, Y., Lanteigne, J. and Chen J., (2015) Effect of Periodic Underloads on Fatigue Crack Growth in Three Steels Used in Hydraulic Turbine Runners, Int. J. of Fatigue 85, DOI: 10.1016/j.ijfatigue.2015.11.027

Huth, H-J, Fatigue Design of Hydraulic Turbine Runners, Doctoral thesis, Fakultet for ingeniørvitenskap og teknologi, 2005

ISO 20816-5:2018 Mechanical vibration - Measurement and evaluation of machine vibration - Part 5: Machine sets in hydraulic power generating and pump-storage plants (2018)

Jabbado, M. Polycyclic fatigue of steel structures: life under varying loads. Mechanics of materials Doctoral thesis of the Ecole Polytechnique, 2006 (In French)

Jacquemoud, R. "Towards a reliable operating range for a Kaplan turbine, beyond the guaranteed range, based accounting for material fatigue damage processes", XVII IA HR symposium, Beijing, China 1994. (in French)

Kokko, V. (2014). Ageing due to start-stop cycles and frequent regulation in lifetime estimation of hydro turbines and generators. SHF, Grenoble.

Lei, X., Yuan, L., Peng, L., Sun, C., Wei, B. and Wei Y., Fatigue endurance limit and crack front evolution in metallic glass, Int. J. Fatigue 143 (2021) 106004.

Ling, Y., Shantz, C., Mahadevan, S. and Sankararaman, S., 2011. Stochastic prediction of fatigue loading using real-time monitoring data. International Journal of Fatigue 33, 868-879. https://doi.org/10.1016/j.ijfatigue.2011.01.015

Liu, X., Luo, Y. and Wang Z., A review on fatigue damage mechanism in hydroturbines, Renewable and Sustainable Energy Reviews 54(2016), 1-14.

Lofflad J., Eissner M. and Graf B. «Strain Gauge measurements of rotating parts with telemetry » 9th International Conference on Hydraulic Efficency Measurements, Trondheim, 2014.

Luna-Ramírez A., Campos-Amezcua A., Dorantes-Gómez O., Mazur-Czerwiec Z., Muñoz-Quezada R., Failure analysis of runner blades in a Francis hydraulic turbine - Case study, Engineering Failure Analysis, Vol. 59, 2016, pp 314-325. https://doi.org/10.1016/j.engfailanal.2015.10.020

Marcouiller, L. \& Thibault, D. «Obtaining stress measurements on runners as a key contribution to reducing their degradation and improving the reliability of hydroelectric production units » HYDRO conference, Bordeaux, 2015.

Matsuishi, M. \& Endo, T. (1969), «Fatigue of metals subjected to varying stress », In Proceedings of the Kyushu Branch of Japan Soc. of Mech. Engrg, Fukuoka, Japan (in Japanese), 37-40.

Mjølsnes, J. "Frequent Start/Stop. Costs for Hydropower Generators," Statkraft Engineering, Report 99/87, Sept. 1999 (in Norwegian). 
Morissette, J.F., Chamberland-Lauzon J., Nennemann B., Monette C., Giroux A.M., Coutu A. and Nicolle J., Stress predictions in a Francis turbine at no-load operating regime, 28th IAHR symposium on Hydraulic Machinery and Systems, 2016, doi:10.1088/1755-1315/49/7/072016

Nicolet, C., Avellan, F., Allenbach, P., Sapin, A., Simond, J.-J., Kvicinsky, S., and Crahan, M. Simulation of transient phenomena in Francis turbine power plants: hydroelectric interaction, 1-12. 13th conference on Waterpower, July 29-31, 2003 in Buffalo, New York, USA.

Nilsson, O. \& Sjelvgren, D. (1997). Hydropower unit startup costs. IEEE Transactions on Power Systems.

Savin, O., Badina, C., Baroth, J., Charbonnier, S. and Bérenguer, C., Start and stop costs for hydro power plants: a critical review, Proc. of the 30th Europ. Safety and Reliability Conf. \& the 15 th Prob. Safety Assessment and Management Conf., 2020.

Schijve, J., Statistical distribution functions and fatigue of structures, Int. J. Fatigue 27 (2005) 10311039.

Seddik, R., Ben Sghaier, R., Atig, A. and Fathallah, R., Fatigue reliability prediction of metallic shot peened-parts based on Wöhler curve, Journal of Constructional Steel Research 130 (2017) 222-233

Sonsino, C.M. \& Dieterich, K., Fatigue strength of steel types G - X5CrNi 134 and G - X5CrNi 174 used for blades of water - power turbines and pumps, Werkstoffe und Korrosion 41, 330-342, 1990.

Sudret, B. (2011). Probabilistic design of structures submitted to fatigue, Fatigue of materials and structures, chapter 5 (C. Bathias and A. Pineau (Eds)), 223_263. Wiley \& Sons.

Susmel, L. Modified Wöhler Curve Method, theory of critical distances and Eurocode 3: a novel engineering procedure to predict the lifetime of steel welded joints subjected to both uniaxial and multiaxial fatigue loading. Int J Fatigue 2008; 30: 888-907.

Susmel, L. The Modified Wöhler Curve Method calibrated by using standard fatigue curves and applied in conjunction with the theory of critical distances to estimate fatigue lifetime of aluminium weldments. Int. J. Fatigue 2009; 31: 197-212.

Yung-Li, Lee, Y.-L. and Tjhung, T. A new definition of the rainflow cycle counting method, Metal Fatigue Analysis Handbook, 89-114, 2012.

Welte, T. Deterioration and maintenance models for components in hydropower plants, Doctoral thesis, Norwegian University of Science and Technology (NTNU), 2008.

Wöhler, A., 1860. Versuche zur Ermittlung der auf die Eisenbahnwagenachsen einwirkenden Kräfte und die Widerstands higkeit der Wagen-Achsen. Zitschrift für Bauwesen, Vol. 10, 583- 616. (In German). 